\title{
HABERMAS VERSUS APEL: ACERCA DA INTERPRETAÇÃO DA UNIVERSALIDADE DO CONTRATO SOCIAL
}

\author{
Juliano Cordeiro da Costa Oliveira ${ }^{1}$
}

\begin{abstract}
Resumo:
Nosso artigo objetiva debater as interpretações de Jürgen Habermas e de Karl-Otto Apel acerca da possível universalidade presente na obra Do Contrato social, de Rousseau. Segundo Habermas, Rousseau e Kant tentaram articular a união prática e a vontade soberana no conceito de autonomia, de modo que a ideia dos direitos humanos e o princípio da soberania popular se interpretassem mutuamente. Mesmo assim, para Habermas, eles não conseguiram entrelaçar simetricamente os dois conceitos. Kant, de acordo com Habermas, sugeriu um modo de ler a autonomia política que se aproximou mais do liberalismo, ao passo que Rousseau do republicanismo. Habermas defende uma possível universalidade no pensamento de Rousseau, a partir de uma síntese com Kant. Dessa maneira, a autonomia privada e a pública pressupõem-se mutuamente, sem que os direitos humanos possam reivindicar um primado sobre a soberania popular, nem esta última sobre os direitos humanos. Ambos seriam, para Habermas, princípios complementares, e não necessariamente antagônicos entre si. Todavia, Karl-Otto Apel considera a posição de Habermas, de uma síntese entre Kant e Rousseau, passível de sérias críticas. Ele enfatiza que a soberania do Contrato social de Rousseau, como soberania de um estado particular, não pode ser identificada com a concepção de vontade geral. A postura de Rousseau, segundo Apel, nos levaria inevitavelmente ao nacionalismo, e não ao universalismo, como em Kant. Apel considera que há, em Rousseau, um particularismo intrínseco do princípio da soberania popular incompatível com os direitos humanos, enquanto Habermas defende a cooriginalidade entre direitos humanos e soberania popular. Este artigo pretende discutir, portanto, como os dois representantes da chamada Ética do Discurso interpretam o pensamento de Rousseau.
\end{abstract}

Palavras-chave: Rousseau. Habermas. Apel. Contrato Social.

\section{HABERMAS VERSUS APEL: CONCENING SOCIAL CONTRACT UNIVERSALITY INTERPRETATION}

\begin{abstract}
:
This article aims to discuss the interpretations of Jürgen Habermas and Karl-Otto Apel concerning the possible universality present in Rousseau's Social Contract. According to Habermas, Rousseau and Kant tried to articulate the practical union and sovereign will in the concept of autonomy, so that the idea of human rights and the principle of popular sovereignty could be mutually interpreted. Even so, for Habermas, they failed to symmetrically interweave the two concepts. Kant, according to Habermas, suggested a way of reading the political autonomy that would come closer to liberalism, while Rousseau's, on the other hand, would come closer to republicanism. Habermas defends a possible universality in Rousseau's thought, from a synthesis with Kant. This way, private and public autonomy presuppose each other, in a way that human rights are not able to claim a primacy over popular sovereignty, nor the latter over human rights. Both would be, for Habermas, complementary principles, and not necessarily antagonistic to each other. However, Karl-Otto Apel considers Habermas's position as a synthesis between Kant and Rousseau, subject to serious criticism. He emphasizes that the sovereignty of Rousseau's Social Contract, as sovereignty of a particular state, can not be identified with the conception of general will. Rousseau's position, according to Apel, would inevitably lead us to nationalism, not to universalism, as in Kant. Apel considers that there is, in Rousseau, an intrinsic particularism of the principle of popular sovereignty incompatible with human rights, whereas Habermas defends the co-originality between human rights and popular sovereignty. This article intends to discuss, therefore, how the two representatives of the so-called Discourse Ethics interpret Rousseau's thinking.
\end{abstract}

Keywords: Rousseau. Habermas. Apel. Social contract.

1 Doutor em Filosofia pela Universidade Federal do Ceará (UFC), com Doutorado Sanduíche pela LudwigMaximilian-Universität (LMU), em Munique, Alemanha. Pós-doutorando pela Universidade Federal do Piauí (UFPI) e Bolsista Capes. E-mail: julianopesquisa81@gmail.com; julianocordeiro81@gmail.com. 


\section{Introdução}

Rousseau (1978b) primeiramente diferencia as desigualdades existentes entre os homens. A primeira, advinda do estado de natureza, denominada por ele de desigualdade natural ou física, consiste na diferença das idades, da saúde, das forças do corpo e das qualidades do espírito e da alma. Já a segunda, denominada de desigualdade moral ou política, depende da convenção que é estabelecida pelos homens na sociedade civil. Por exemplo: a diferença de poder entre os homens e a diferença social (ricos e pobres). Para Rousseau (1978b), a desigualdade política passa a existir à medida que o homem deixa o estado de natureza, tendo na propriedade privada o verdadeiro fundamento da sociedade civil:

\footnotetext{
O verdadeiro fundador da sociedade civil foi o primeiro que, tendo cercado um terreno, lembrou-se de dizer isto é meu e encontrou pessoas suficientemente simples para acreditá-lo. Quantos crimes, guerras, assassínios, misérias e horrores não pouparia ao gênero humano aquele que, arrancando as estacas ou enchendo o fosso, tivesse gritado a seus semelhantes: "Defendei-vos de ouvir esse impostor: estareis perdidos se esquecerdes que os frutos são de todos e que a terra não pertence a ninguém" (ROUSSEAU, 1978b, p.259).
}

A partir do fundamento da propriedade privada, há, na sociedade civil, a institucionalização de leis injustas, não legítimas, sujeitando "todo gênero humano ao trabalho, à servidão e à miséria" (ROUSSEAU, 1978b, p.270). Tais leis são legais, isto é, oficializadas pelo Estado, contudo, não são legítimas, como defende Rousseau. E de que modo o poder torna-se legítimo? Em Rousseau, não se trata simplesmente de retornar ao estado de natureza, mas sim de tornar possível a liberdade e a igualdade existentes outrora (estado de natureza), e não mais na sociedade civil.

É impossível, diz Rousseau (2004), que, no estado de natureza, exista uma diferença de um homem para com outro, de modo que um seja dependente do outro para sobreviver, como há na sociedade civil. Segundo Rousseau (1978a), cabe ao contrato social estabelecer convenções legítimas que regulamentem a vida social de forma a restituir o que foi perdido na passagem do estado de natureza para a sociedade civil. Vale lembrar que tanto as injustiças descritas por Rousseau na sociedade civil como a proposta do contrato social são convenções humanas. Em outras palavras, o contrato social é uma convenção legítima e consciente de todo o povo contra outra convenção não legítima, injusta, porém legal, existente na sociedade civil (ABREU, 2007).

\begin{tabular}{|l|l|l|l|l|}
\hline Qevista Dialectus & Ano 8 & n. 15 & Agosto - Dezembro 2019 & p. 97-108 \\
\hline
\end{tabular}


A proposta de Rousseau é, enfim, constituir um poder fundamentado na vontade geral. O contrato social de Rousseau é, portanto, um artifício para desfazer outro artifício (ABREU, 2007). Ora, se as desigualdades da sociedade civil se baseiam em interesses particulares constituídos historicamente e socialmente, como a propriedade privada, os males desta mesma sociedade civil podem também ser desfeitos em prol de outros interesses, a saber, os da vontade geral. É justamente pelo fato de as leis serem convenções que elas podem ser modificadas, tendo, em Rousseau, a vontade geral como critério de verdade, justiça e legitimidade. E o que vem a ser a vontade geral?

Ela é aquela que traduz o que há de comum em todas as vontades individuais, tendendo sempre à utilidade pública. Ela é o substrato coletivo das consciências. Entretanto, Rousseau diferencia vontade geral e vontade de todos. A primeira tem em vista o interesse ou bem comum. Já a segunda não passa de uma soma das vontades particulares que, em alguns casos, pode coincidir ou se aproximar da vontade geral (PINTO, 2005). Tão pouco a vontade geral pode também ser confundida. com a vontade da maioria. Portanto, é a vontade geral que deve dirigir a sociedade, uma vez que ela se sustenta no que há de comum nas vontades individuais (bem comum), tornando o poder legítimo. Rousseau ainda alerta acerca do perigo da formação de facções que expressam somente vontades individuais, e nunca o interesse geral ou o bem comum. Todo governo legítimo é, em Rousseau, republicano.

No Contrato social, os homens, impossibilitados de subsistirem por seus próprios meios no estado de natureza, unem-se numa forma de associação. Há a intensão de preservar a igualdade do estado de natureza e a liberdade, sendo que esta última apenas se transforma: em lugar da liberdade natural, irrestrita, instala-se, no contrato social, uma liberdade convencional, uma existência livre, porém, socializada. "O homem nasce livre, e por toda a parte encontra-se a ferros. O que se crê senhor dos demais, não deixa de ser mais escravo do que eles" (ROUSSEAU, 1978a, p.22).

Segundo Rousseau, a força não faz o direito. Devemos obedecer apenas aos poderes legítimos, fruto da vontade geral e soberana do povo. Resta-nos, assim, somente as convenções à luz da vontade geral. É preciso encontrar uma forma de associação que defenda e proteja a pessoa e os bens de cada associado com toda a força comum, e pela qual cada um, unindo-se a todos, só obedece, contudo, a si mesmo, permanecendo assim tão livre como antes. Aqui encontra-se "o problema fundamental cuja solução o contrato social oferece" (ROUSSEAU, 1978a, p.32). Em Rousseau, há uma radical crítica à representação política, de modo que, como veremos, onde há o representante não há mais o representado. $\mathrm{A}$

\begin{tabular}{|l|l|l|l|l|}
\hline Q Ponita Dialectus & Ano 8 & n. 15 & Agosto-Dezembro 2019 & p. 97-108 \\
\hline
\end{tabular}


legitimidade, em Rousseau, relaciona-se com a ideia de um povo que se autodetermina a partir de uma comunidade autoconsciente.

Nesse contexto, Jürgen Habermas considera que tanto Rousseau como Kant tentaram articular a união prática e a vontade soberana no conceito de autonomia, de modo que a ideia liberal dos direitos humanos e o princípio republicano da soberania popular se interpretassem mutuamente. Mesmo assim, para Habermas, eles não conseguiram entrelaçar simetricamente os dois conceitos. Kant, de acordo com Habermas, sugeriu um modo de ler a autonomia política que se aproximou mais do liberalismo, ao passo que Rousseau do republicanismo. Habermas defende uma possível universalidade no pensamento de Rousseau, a partir de uma síntese com Kant (OLIVEIRA, 2012).

Em Habermas, a autonomia privada e a pública pressupõem-se mutuamente, sem que os direitos humanos possam reivindicar um primado sobre a soberania popular, nem esta última sobre os direitos humanos. Ambos seriam, para Habermas, princípios complementares, e não necessariamente antagônicos entre si. Porém, Karl-Otto Apel considera a posição de Habermas, de uma síntese entre Kant e Rousseau, passível de sérias críticas. Ele argumenta que a postura de Rousseau nos levaria ao nacionalismo, e não ao universalismo, como em Kant. Apel considera que há, em Rousseau, um particularismo intrínseco do princípio da soberania popular incompatível com os direitos humanos, enquanto Habermas defende a cooriginalidade entre direitos humanos e soberania popular. Este artigo pretende discutir, portanto, como os dois representantes da chamada Ética do Discurso interpretam o pensamento de Rousseau, acerca da possível universalidade presente no Contrato social.

\section{Rousseau: poder comunicativo e soberania popular}

Habermas (2002), acerca da visão republicana de Rousseau, demonstra que a política é constitutiva do processo de coletivização social como um todo. O republicanismo defende princípios de participação e comunicação que possibilitam a autodeterminação dos cidadãos. Concebe-se a política como forma de reflexão sobre um contexto de vida ético. Habermas destaca que ela constitui o medium em que os integrantes de comunidades solidárias, surgidas de forma natural, conscientizam-se de sua interdependência mútua. No republicanismo, a formação da vontade tem a função de constituir a sociedade como uma coletividade política e de manter viva a cada eleição a lembrança desse ato fundador.

\begin{tabular}{|l|l|l|l|l|}
\hline Qovista Dialectus & Ano 8 & n. 15 & Agosto - Dezembro 2019 & p. 97-108 \\
\hline
\end{tabular}


Desse modo, os cidadãos dão forma e prosseguimento às relações preexistentes de reconhecimento mútuo, transformando-as, de forma voluntária e consciente, em uma associação de jurisconsortes livres e iguais. Os representantes de um humanismo republicano dão destaque ao valor próprio, não instrumentalizável, da auto-organização dos cidadãos, de modo que, aos olhos de uma comunidade naturalmente política, os direitos humanos só se tornam obrigatórios como elementos de sua própria tradição, assumida conscientemente.

$\mathrm{Na}$ interpretação republicana, a formação democrática da vontade se realiza na forma de um autoentendimento ético-político. Então, a liberdade se relaciona com a autonomia do povo soberano que se autodetermina. De acordo com a leitura habermasiana do republicanismo de Rousseau, há uma ênfase na autonomia pública em relação à privada, como também na soberania do povo em contraposição aos direitos humanos. A formação política da vontade constitui o medium através do qual a sociedade se entende como um todo estruturado politicamente. O republicanismo, contextualiza Habermas, sempre colocou a liberdade antiga (da comunidade) na frente da liberdade moderna (do indivíduo).

No republicanismo, a sociedade é por si mesma sociedade política - societas civilis; pois, na prática de autodeterminação política, a comunidade toma consciência de si mesma, por meio da vontade coletiva dos sujeitos. Nesse sentido, o indivíduo, para o republicanismo, não possui o mesmo sentido dos liberais, haja vista que aqui o indivíduo encontra-se, desde sempre, numa convivência com outros sujeitos: a vida em comum tem seu fundamento na comunidade, e não no indivíduo como instância de autorreferência.

No modelo republicano, há uma base social autônoma por parte dos cidadãos, que independe da administração pública e da mobilidade socioeconômica privada, impedindo a comunicação política de ser tragada pelo Estado e assimilada totalmente pelo mercado. A democracia, no sentido republicano, tem como fundamento a auto-organização política da sociedade. Disso resulta uma compreensão de política dirigida polemicamente contra o aparelho do Estado. Na interpretação republicana, o povo é o titular de uma soberania que não se deixa representar: o poder constituinte baseia-se na prática de autodeterminação das pessoas privadas, não de seus representantes.

Habermas, por isso, cita Rousseau, tal qual um dos nomes fundamentais do republicanismo para as reflexões políticas contemporâneas. De acordo com Rousseau, só a vontade geral pode dirigir as forças do Estado, tendo em vista o bem comum. No capítulo I, intitulado A soberania é inalienável, do Livro Segundo do Contrato social, Rousseau afirma que o soberano é um ser coletivo, movido pela vontade geral. A soberania da vontade geral só

\begin{tabular}{|l|l|l|l|l|}
\hline Q Ponista Dialectus & Ano 8 & n. 15 & Agosto-Dezembro 2019 & p. $97-108$ \\
\hline
\end{tabular}


pode ser representada por ela mesma. "A soberania é indivisível pela mesma razão por que é inalienável, pois a vontade ou é geral, ou não o é; ou é a do corpo do povo, ou somente de uma parte” (ROUSSEAU, 1978a, p. 44). É nula, explica Rousseau, toda lei que o povo diretamente não ratificar.

Segundo Rousseau, o povo, submetido às leis, deve ser o seu autor. Só àqueles que se associam cabe regulamentar as condições da sociedade. Por isso, não pode ser considerado livre um povo que possui representantes.

\footnotetext{
Afirmo, pois, que a soberania, não sendo senão o exercício da vontade geral, jamais pode alienar-se, e que o soberano, que nada é senão um ser coletivo, só pode ser representado por si mesmo. O poder pode transmitir-se; não, porém, a vontade (ROUSSEAU, 1978a, p. 43-44).
}

Além disso, Rousseau enfatiza que cada povo pode ter um sistema particular de instituições. "Em uma palavra, além das máximas comuns a todos, cada povo reúne em si alguma coisa que o dirige de modo todo especial e torna sua legislação adequada somente a si mesmo" (ROUSSEAU, 1978a, p. 68). Tal perspectiva, por exemplo, pode ser identificada nas correntes filosóficas contemporâneas do comunitarismo e do multiculturalismo.

Para Rousseau, o poder pertence ao povo e não pode pertencer senão a ele. Há, na política republicana, uma dependência do poder administrativo em relação ao comunicativo, decorrente do processo de formação da vontade e opinião pública. Ou seja, o paradigma da política republicana não é o mercado, e sim a interlocução entre os cidadãos.

No entendimento republicano, a formação política da opinião e da vontade, na esfera pública e no parlamento, não obedece às estruturas de processos do mercado, mas às estruturas próprias de uma comunicação pública orientada pelo entendimento. Para a política no sentido de uma prática de autodeterminação de cidadãos, o paradigma não é o mercado, mas o do diálogo (HABERMAS, 1997a, p. 338).

Nada mais perigoso, diz Rousseau, que a influência dos interesses privados nos negócios públicos. Nesse sentido, há menos centralização do poder administrativo e estatal, em prol da capacidade comunicativa dos cidadãos. Esse aspecto é o que Habermas considera positivo no modelo republicano (OLIVEIRA, 2017). Ele argumenta que o modelo republicano de política tem a seu favor o fato de se firmar no sentido radicalmente democrático de uma auto-organização da sociedade pelos cidadãos, por via comunicativa, não remetendo os fins coletivos somente a uma negociação entre interesses particulares opostos. Em Rousseau, há

\begin{tabular}{|l|l|l|l|l|}
\hline Qevista Dialectus & Ano 8 & n. 15 & Agosto - Dezembro 2019 & p. 97-108 \\
\hline
\end{tabular}


uma radical crítica à representação, pois uma verdadeira democracia acontece apenas à medida que o povo participa diretamente das decisões.

A ideia de representantes, explica Rousseau, é moderna, vindo também do governo feudal. Nas antigas repúblicas, diz ele, jamais o povo teve representantes, não se conhecendo tal palavra: "De qualquer modo, no momento em que um povo se dá representantes, não é mais livre; não mais existe” (ROUSSEAU, 1978a, p. 100).

Portanto, em Rousseau, há a valorização da chamada liberdade dos antigos, ou seja, a liberdade da comunidade, porquanto o verdadeiro fundamento da sociedade faz-se por meio do povo. Rousseau fala acerca de um eu comum que caracteriza a vontade do povo. Essa pessoa pública, que se forma pela união de todas as outras, explica ele, tomava antigamente o nome de cidade, assumindo hoje a designação de república ou de corpo político.

Para Habermas, entretanto, há uma sobrecarga ética do cidadão em Rousseau, que conta com virtudes políticas ancoradas no ethos de uma comunidade mais ou menos homogênea, integrada através de tradições culturais comuns, algo insustentável, para Habermas, em sociedades plurais e complexas. Segundo ele, o liberalismo e o republicanismo possuem respostas insuficientes para tal questão, à medida que o primeiro enfatiza apenas as liberdades individuais, e o segundo tão somente as da comunidade. Seria preciso, a um só instante, estabelecer um conceito de política que destacasse ambas as perspectivas, ou seja, os direitos humanos com a soberania popular (OLIVEIRA, 2018).

A conexão entre poder comunicativo e direito legítimo faz com que os cidadãos não recorram a seus direitos democráticos exclusivamente como se eles fossem liberdades subjetivas (direitos liberais), mas sim como autorizações legítimas para o emprego público das liberdades comunicativas. Em Habermas, há necessariamente uma interligação entre poder produzido comunicativamente e normatização jurídica, que, por sua vez, deve garantir, ao mesmo tempo, o direito à liberdade comunicativa e o direito de participação dos sujeitos nas deliberações, almejando uma reciprocidade entre autonomia pública e privada.

A cooriginalidade da autonomia privada e pública somente se mostra quando
conseguimos decifrar o modelo da auto-legislação [sic] através da teoria do discurso,
que ensina serem os destinatários simultaneamente os autores de seus direitos. A
substância dos direitos humanos insere-se, então, nas condições formais para a
institucionalização jurídica desse tipo de formação discursiva da opinião e da
vontade, na qual a soberania do povo assume figura jurídica. (HABERMAS, 1997a,
p. 139).

Segundo Habermas, as próprias formas de comunicação, que tornam possível a formação discursiva de uma vontade política racional, necessitam de uma institucionalização

\begin{tabular}{|c|c|c|c|c|}
\hline Qovista Dialeatus & Ano 8 & n. 15 & Agosto - Dezembro 2019 & p. $97-108$ \\
\hline
\end{tabular}


jurídica. A ideia democrática da autolegislação não tem opção senão validar-se a si mesma no medium do direito. A autolegislação de herança republicana conecta-se com o medium do direito, a fim de que os sujeitos institucionalizem juridicamente os pressupostos comunicativos e os procedimentos de um processo de formação da opinião e da vontade, no qual é possível aplicar o princípio do discurso.

\begin{abstract}
Desse modo, as autonomias privada e pública pressupõem-se reciprocamente. O nexo interno da democracia com o Estado de direito consiste no fato de que, por um lado, os cidadãos só poderão utilizar condizentemente a sua autonomia pública se forem suficientemente independentes graças a uma autonomia privada assegurada de modo igualitário. Por outro lado, só poderão usufruir de modo igualitário da autonomia privada se eles, como cidadãos, fizerem um uso adequado da sua autonomia política (HABERMAS, 2001, p.49).
\end{abstract}

Habermas percorre, assim, um caminho entre Kant e Rousseau, na tentativa de uma síntese entre ambas as tradições.

\title{
Habermas: entre Kant e Rousseau
}

Segundo Habermas, Rousseau e Kant tentaram articular a união prática e a vontade soberana no conceito de autonomia, de modo que a ideia dos direitos humanos e o princípio da soberania do povo se interpretassem mutuamente. Mesmo assim, para Habermas, eles não conseguiram entrelaçar simetricamente os dois conceitos. Kant, de acordo com Habermas, sugeriu um modo de ler a autonomia política que se aproxima mais do liberalismo, ao passo que Rousseau se aproximou mais do republicanismo.

Além disso, o liberalismo e o republicanismo ainda estariam presos a uma concepção de filosofia do sujeito e da consciência: o liberalismo centra-se no indivíduo; e o republicanismo, na comunidade ética. Habermas tenta acolher elementos de ambos os lados, integrando-os no contexto de um procedimento ideal para as tomadas de decisão.

Em consonância com o republicanismo de Rousseau, Habermas defende uma posição central para o processo político de formação da opinião e da vontade, sem, no entanto, entender a constituição jurídico-estatal como algo secundário. Habermas concebe os direitos fundamentais e os princípios do Estado de direito como uma resposta consequente à pergunta sobre como institucionalizar as exigentes condições de comunicação do procedimento democrático. Por um lado, o poder político depende do direito para se legitimar. Por outro, o direito necessita do aparato político estatal para ser posto.

\begin{tabular}{|l|l|l|l|l|}
\hline Q Ponista Dialectus & Ano 8 & n. 15 & Agosto-Dezembro 2019 & p. 97-108 \\
\hline
\end{tabular}


Todavia, Karl-Otto Apel considera a posição de Habermas, de uma síntese entre Kant e Rousseau, passível de sérias críticas. A ideia da soberania popular de Rousseau conteria em si mesma a perspectiva da universalidade? A soberania popular não nos levaria a priori ao nacionalismo? Ou haveria, ao contrário, a possibilidade de uma universalidade na soberania popular por caminhos kantianos, como defende Habermas?

\section{Apel e a impossibilidade da universalidade no Contrato Social}

Apel considera a proposta habermasiana de síntese entre Rousseau e Kant passível de várias críticas, não só do ponto de vista normativo, mas também do histórico-sociológico e funcional. Para Apel (2004), o princípio da democracia não se identifica com o do direito, que Habermas apontou no sentido de uma diferenciação distintiva como cooriginário. O princípio da democracia representaria, segundo Apel (2004), um fenômeno histórico-contingente maior do que o direito. Isso se revelaria no fato de que ainda hoje numerosos Estados pretendem ser "Estados de Direito", sem aceitar o "preconceito", segundo eles, eurocêntrico do princípio da democracia liberal.

Apel (2004) enfatiza que a soberania do Contrato social de Rousseau, como soberania de um estado particular, não pode ser identificada com a concepção de vontade geral. Kant, a partir de sua reserva ao princípio da democracia, orientado empiricamente, identificou a vontade geral com a ideia reguladora de um consenso universal de todos os sujeitos de uma fundação fictícia do Estado. Tal ideia seria realizável apenas aproximativamente, no contexto de uma ordem cosmopolita do direito e da paz, enquanto que a postura de Rousseau conduziria ao nacionalismo. Para Apel, o princípio do direito não pode ser simplesmente identificado com o da democracia, como Habermas pretende:

Em minha opinião, a 'autonomia política', apesar de sua relação interna constitutiva
para a forma democrática de Estado, com a 'autonomia moral', é também
constituída sempre - isto é, de modo completamente independente de uma 'ética
política' no sentido do comunitarismo - por um princípio político: o princípio da
diferenciação distintiva de sistemas particulares de poder. Nessa medida, a
autonomia política, enquanto existirem Estados particulares (mesmo que sejam
Estados multiculturais!), não pode ter a mesma categoria quanto à fundamentação da
validade universal como tem - no sentido de Kant - a 'autonomia moral' (APEL,
2004, p.237).

Habermas, no entanto, persegue a ideia de legitimação do Estado democrático de direito, de tal modo que os direitos humanos e a soberania popular exerçam funções distintas,

\begin{tabular}{|l|l|l|l|l|}
\hline Q Rovista Dialectus & Ano 8 & n. 15 & Agosto - Dezembro 2019 & p. $97-108$ \\
\hline
\end{tabular}


mas complementares. Em Habermas, há uma conciliação entre a ideia do direito liberal com a da democracia republicana. Contudo, Apel explica que tal proposta é inconcebível, uma vez que o princípio do direito não pode ser simplesmente identificado com o da democracia, como Habermas assim o faz. Apel considera que há, em Rousseau, um particularismo intrínseco do princípio da soberania do povo incompatível com os direitos humanos. Há uma passagem bastante significativa no Contrato social que exemplifica a interpretação de Apel:

Sobre tais relações, precisa-se conceder a cada povo um sistema particular de instituição que seja o melhor, não talvez em si mesmo, mas para o Estado a que se destina. [...] Em uma palavra, além das máximas comuns a todos, cada povo reúne em si alguma coisa que o dirige de modo todo especial e torna sua legislação adequada somente a si mesmo. (ROUSSEAU, 1978a, p. 67-68).

Em Rousseau, há uma variedade de situações que pode levar à relatividade das formas constitucionais de governo. "Isso mostra não haver uma constituição de Governo única e absoluta, mas que podem existir tantos Governos diferentes pela natureza quantos Estados diferentes pelo tamanho" (ROUSSEAU, 1978a, p.77). Segundo Rousseau, a democracia convém a Estados pequenos; a aristocracia aos médios; e a monarquia aos grandes. O essencial, para Rousseau, não são as formas em si de governo, pois elas podem variar de acordo com as circunstâncias. Ou seja, não seria a forma de governo que definiria a priori a vontade geral. Esta, em realidade, teria predominância em relação à forma de governo.

Rousseau defende, inclusive, a ditadura, no sentido romano do termo, em casos específicos e de urgência, sem que a vontade geral seja posta em questão: muda-se apenas a forma de acordo com as situações específicas, desde que a vontade geral permaneça a fonte do poder. Tais passagens acima favorecem, de fato, a interpretação de Apel contra Habermas, pois Rousseau favoreceria o relativismo das comunidades, em contraposição ao princípio dos direitos humanos oriundo da tradição liberal e universalista.

\section{Conclusão}

Em Habermas, como vimos, quando se admite que a autonomia privada e a pública são cooriginárias, tal relação só pode ser determinada, em última instância, pelos cidadãos que deliberam acerca das questões, havendo também uma conciliação entre soberania popular e direitos humanos. Dessa maneira, de acordo com a interpretação habermasiana, a autonomia privada e a pública pressupõem-se mutuamente, sem que os

\begin{tabular}{|l|l|l|l|l|}
\hline Qenista Dialectus & Ano 8 & n. 15 & Agosto-Dezembro 2019 & p. 97-108 \\
\hline
\end{tabular}


direitos humanos possam reivindicar um primado sobre a soberania popular, nem esta última sobre os direitos humanos. Então, na ótica habermasiana, há uma necessária coesão entre Estado de direito liberal e democracia republicana:

Os direitos humanos da tradição liberal e a soberania popular do republicanismo seriam, para Habermas, princípios complementares, e não necessariamente antagônicos. A proposta habermasiana fundamenta-se, em outras palavras, na tentativa de uma síntese entre Rousseau e Kant, ou seja, entre a soberania popular e os direitos humanos, entre a liberdade doa antigos e a dos modernos.

Já para Apel a tentativa de Habermas, de uma síntese entre Kant e Rousseau, seria passível de várias críticas, uma vez que, segundo Apel, há, em Rousseau, um particularismo intrínseco do princípio da soberania do povo incompatível com os direitos humanos, como vimos ao longo do texto. Para Apel, o princípio do direito não pode ser simplesmente identificado com o da democracia, como Habermas pretende.

\section{Referências:}

ABREU, M. Representação em Rousseau e Hannah Arendt. Lua Nova, São Paulo, n. 72, p. 175-194, 2007.

APEL, K.-O. Dissolução da ética do discurso? In: APEL, K.-O.; OLIVEIRA, M. A.; MOREIRA, L. (Org.). Com Habermas, contra Habermas: direito, discurso e democracia. São Paulo: Landy, 2004, p. 201-321.

HABERMAS, J. Direito e democracia: entre facticidade e validade. Rio de Janeiro: Tempo Brasileiro, 1997a.v. I.

HABERMAS, J. Direito e democracia: entre facticidade e validade. Rio de Janeiro: Tempo Brasileiro, 1997b. v. II.

HABERMAS, J. A constelação pós-nacional: ensaios políticos. São Paulo: Littera Mundi, 2001.

HABERMAS, J. A Inclusão do outro: estudos de teoria política. São Paulo: Loyola, 2002.

OLIVEIRA, J. Do republicanismo à política deliberativa: a condição da democracia em JeanJacques Rousseau e Jürgen Habermas. Rev. Humanidades, Fortaleza, v. 27, n. 1, jan./jun. 2012, p.181-195.

OLIVEIRA, J. Entre o liberalismo e o republicanismo: Habermas e a democracia deliberativa. Revista Dialectus, Fortaleza, n.11, ago/dez. 2017, p.280-296.

\begin{tabular}{|l|l|l|l|l|}
\hline Q Povista Dialectus & Ano 8 & n. 15 & Agosto - Dezembro 2019 & p. 97-108 \\
\hline
\end{tabular}


OLIVEIRA, J. Secularismo e Religião na Democracia Deliberativa de Habermas: da pragmática ao déficit ontológico e metafísico. Porto Alegre/Teresina: Fi/EDUFPI, 2018.

PINTO, M. A Noção de vontade geral e seu papel no pensamento político de Jean-Jacques Rousseau. Cadernos de Ética e Filosofia Política, São Paulo, n. 7, p. 81-97, 2005.

ROUSSEAU, J.-J. Do contrato social. 2. ed. São Paulo: Abril Cultural, 1978a. (Os Pensadores).

ROUSSEAU, J.-J. Discurso sobre a origem e os fundamentos da desigualdade entre os homens. 2. ed. São Paulo: Abril Cultural, 1978b. (Os Pensadores).

ROUSSEAU, J.-J. Emílio ou da educação. 3. ed. São Paulo: Martins Fontes, 2004. 